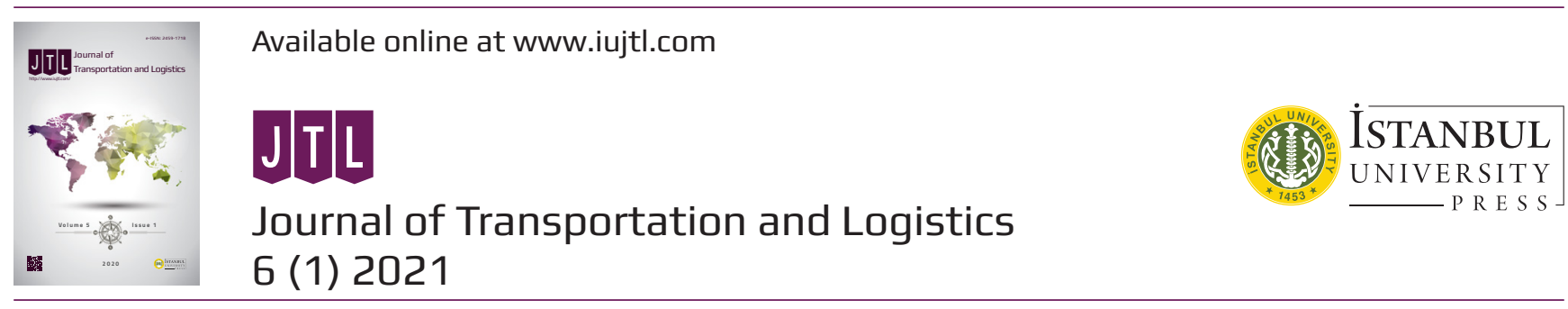

\title{
Visualization of the Global Supply Chain Research Domain Through Bibliometric Analysis
}

\author{
Bibliyometrik Analiz Yoluyla Küresel Tedarik Zinciri Araștırma Alanının Görselleștirilmesi
}

Serdar Semih Coșkun¹ ${ }^{10}$, Halim Kazan² $\mathbb{0}$

\begin{abstract}
Over the past three decades, it has become clear that supply chain networks have surpassed borders and expanded significantly in the international arena. The effects of this transformation have been the subject of many academic studies. The aim of this study is to understand how the domain knowledge of global supply chain literature has grown and evolved over time. Through co-citation analysis using CiteSpace software, a literature cognitive map has been extracted and hotspot topics, emerging trends and burst cited articles have been discovered in this map. The secondary data (including 653 research papers and 18,197 references) used in the analysis was retrieved from the Web of Science database. The results indicate that the sub-topics "greenhouse gas emission", "corporate social responsibility" and "fair-trade labeling scheme" are new emerging trends in research of global supply chains. Also, the research focus has been sliding from cost reduction - profit maximization issues towards environmental and social issues under the sustainable supply chain management theory. Our study aims to provide a better understanding of current problems in the global supply chain area and lead to future research.
\end{abstract} Keywords: Global Supply Chains, Scientometrics, CiteSpace Jel Classifications: M16, C55, F64 


\section{Introduction}

The global supply chain concept refers to the global links between an organization, its suppliers, and customers from all over the world. Due to the rapid evaluation of business sectors, a great deal of goods and services are produced by collaborations, but not by single organizations. Today, even small components of a particular product are subcontracted to specialized suppliers. Also, this deterioration exceeds the borders of nations very quickly (Dietzenbacher, Los, Stehrer, Timmer, and De Vries, 2013; Gereffi, Humphrey, and Sturgeon, 2005). In this sense, global supply chain management has become accepted as the most popular operation strategy contributing to the competitiveness of organizations (Gunasekaran, Lai, and Cheng, 2008). It is also stated that the globalization process enhances income revenue by penetrating new markets and providing access to suppliers in order to cater raw materials and semi-products with lower costs (Halldórsson et al., 2010). Such strategic initiatives require the integration of retailers, distributors, manufacturers, and suppliers in an effective and efficient manner (Yeung, 2008).

Beside many opportunities, it is inevitable that sharpening complexity of global supply chain networks also evoke a lot of threat within the business environment. As they exceed national boundaries, the designing of either existing or new product lines are more likely to meet challenges of globalization (Meixell and Gargeya, 2005). These challenges disrupt the process of value creation. In this respect, it is very crucial to understand the effects of the deterioration of production on economic, social and environmental outputs across countries and industries. On the other hand, supply chain oriented problems have already become so substantial that many practitioners and scholars have paid attention since the middle of the 1990's (Gunasekaran et al., 2008). The focus of these studies have been on various aspects. They have utilized several business models to put forward a comprehensive insight into the literature. Therefore, it would be helpful to use scientometrics tools to conceive the domain knowledge of global supply chain management literature.

The main objective of this paper is to reveal the cognitive map of global supply chain related studies in which hotspot sub-topics and emerging trends are clarified. This provides a research agenda for the future, illustrating the gaps and limitations of past research. We believe that the evaluation of the existing research over a certain period of time indicates how the problems and solutions actually evolve, so the findings may shed some light on the track of subsequent studies. In this perspective, a scientometrics analysis was conducted within research published under the topic of the global supply chain between 1995 and 2016. More specifically the document co-citation analysis has been applied through CiteSpace software, as it is explained with whole details later on.

\section{Methodology}

\subsection{Scientometric Analysis}

Scientific ideas mostly emerge from the basis of former research. They produce solutions for scientific problems. Thus, reviewing the extant literature is the backbone of a scientific research. The validity of outcomes derived from the research process also depends on to what extent former research supports them (Colepicolo, 2015). Such cause and effect 
relations between succeeding publications requires a kind of communication proceeding through citations (Zuccala, 2006). It is inevitable that this communication aggregates in a scientific network during the period. Beyond the network linkages, there might be "invisible colleges" hidden within a complicated network. The concept of hidden colleges suggests that scholars who propose similar ideas have strong relationships among scientific society, even if they do not officially study together in the same institution (Crane, 1969; Yalçin and Yayla, 2016).

From this point of view, scientometrics is described as a method for measuring the scientific communication of a particular discipline using mathematical and statistical techniques (Pritchard, 1969). Scientometric tools can reveal the invisible colleges in a discipline (Ding, 2011). These tools detect the mathematical patterns on metadata, to visualize the big picture regarding the research topic (Klavans and Boyack, 2011).

\subsection{Co-citation Analysis}

Co-citation is one of bibliographic coupling, which examines the relationships between publications citing the same references. Co-citation analysis enables us to understand the intellectual infrastructure of the knowledge domain regarding periodic transformations (Rorissa and Yuan, 2012; Small, 1973).

In this study, document co-citation analysis was applied. This analysis identifies the top cited publications through scanning the bibliographic dataset (Chen, Song, Yuan, and Zhang, 2008). The evaluation of a particular research field, as well as emerging subresearch fields, can be explored with this method (Chen, Ibekwe-SanJuan, and Hou, 2010). Furthermore, publications that have crucial importance in the network can be identified based on citation frequency.

In this study, CiteSpace was employed to conduct data visualization. CiteSpace is a Javabased freeware developed for visualizing the semantic and social networks in a specific literature (Chen and Leydesdorff, 2014). It has been widely used by researchers from all over the world since it was developed in 2004 (Zhang, Wang, Hao, and Yu, 2016). The underlying attention that scholars pay this tool is because it has powerful illustration features which make it easy to understand the relationships between research items in a specific research topic. Furthermore, CiteSpace was developed for scientific literature reviews, but not for different aims, i.e. finding out the nature of any social network as other social network analysis tools can do. Therefore, CiteSpace shows the best performance in the literature review, among many other social network analysis software (Al, Sezen, and Soydal, 2012). Specifically, CiteSpace conducts a semantic analysis of the dataset, so that milestones and critical paths of knowledge can be discovered. It is also available to choose the analysis of cooperation status between author, institution and country, keywords co-occurrence, author co-citation and document co-citation networks in the same data unit (Zhang et al., 2016).

\subsection{Data Collection}

In this study, 653 research papers and 18,197 references published between 1995 and 2016 were analysed. A dataset of bibliographic records was retrieved from the Web of 
Science Core Collection database. Using a topic search, the information of the author(s), title, source, abstract and cited references were retrieved.

\section{Results}

In order for hotspot research papers and emerging trends to be extracted, the document co-citation analysis was conducted. Figure 1 shows the document co-citation network containing clusters. Each node represents an individual reference. The bigger circle of a certain node means the higher frequency which has been cited so far. The lines between nodes come up when the co-citation occurs. In other words, if a paper simultaneously cites two different references together, then the line between two cited references emerges. As the frequency of co-citation increases, the lines get thicker.

CiteSpace seeks the patterns embedded in the citation relations within the cognitive map of global supply chain literature. Hence, the dataset was divided into 98 co-citation clusters. The cluster names are taken from title words. Index terms label these clusters. Table 1 summarizes the largest 10 clusters of the co-citation network. (TFIDF $=$ term frequencyinverse document frequency; LLR = log-likelihood ratio; $\mathrm{MI}=$ Mutual information). According to these parameters used by underlying layout algorithms, it is possible to extract several clusters labeled the CiteSpace.

As it is seen in Table 1, the ClusterID refers to the cluster codes. The size shows the number of papers in each cluster. Mean year of citation is the age of the cluster. It refers to the renewal of clusters. Silhouette score is the clustering performance of the layout algorithms. The higher silhouette score indicates that elements within a cluster better resemble each other (Kaufman and Rousseeuw, 2009). This score can measure the homogeneity of a cluster. It is noted that the acceptable silhouette score should be a minimum 0.7 points (SIMOVICI, 2007).

Table 2 indicates the top 20 core cited references extracted from global supply chain research. One can comprehend the knowledge domain of the research field by scanning these papers. The citation counts are the number of times other papers have cited this reference in the dataset. Centrality scores show the strategic importance of each paper. Papers with high centrality have a crucial position in the network. The burst scores show the degree of activity volume of a paper along a specific period. In other words, papers with high burst scores are paid a great deal of attention in a short time. 


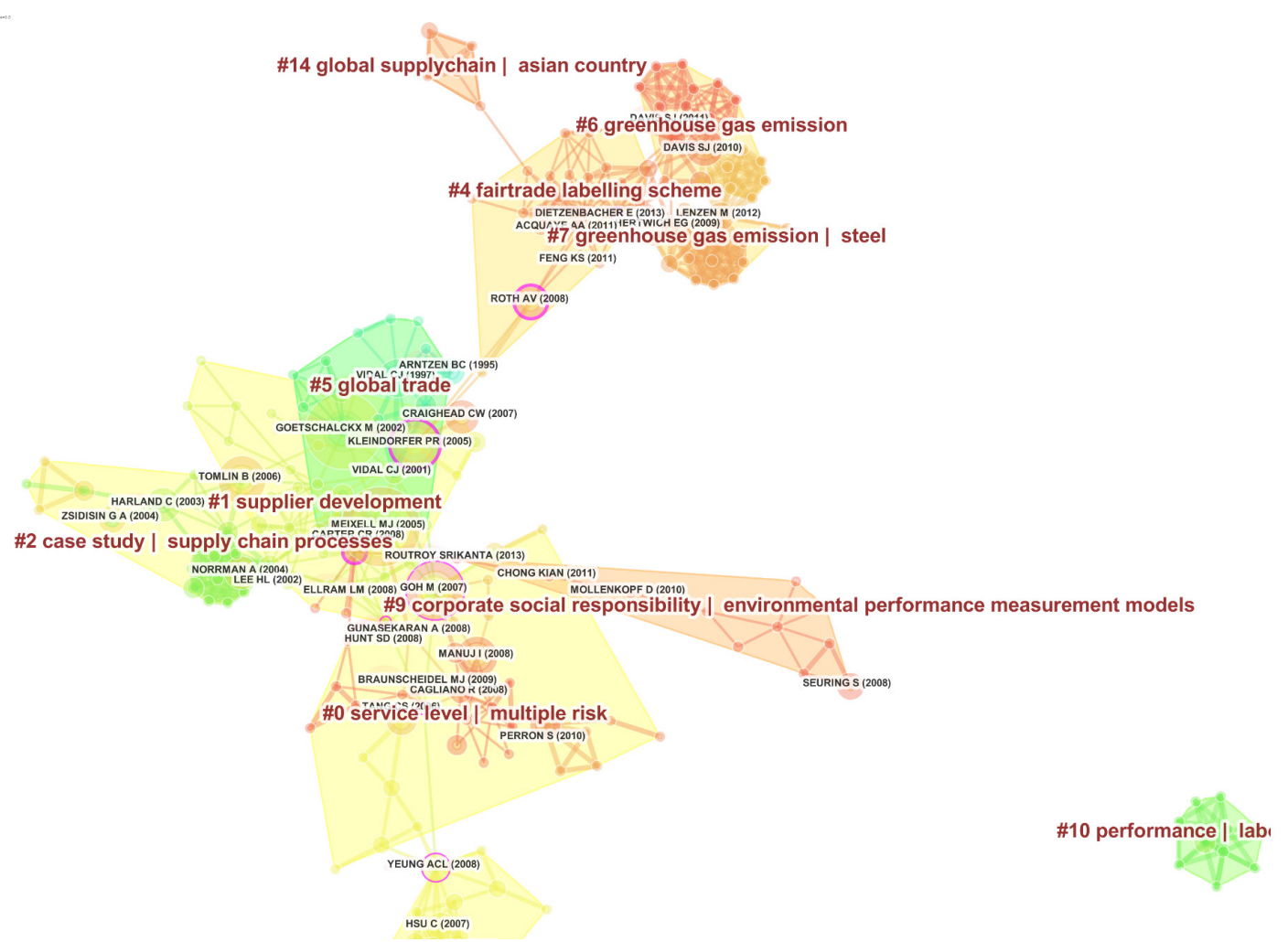

Figure 1. Visualization of co-citation clusters and cited references

Table 1. Summary of largest 10 emerging clusters from 1995 to 2016

\begin{tabular}{|c|c|c|c|c|c|c|}
\hline \multirow{2}{*}{ ClusterID } & \multirow{2}{*}{ Size } & \multirow{2}{*}{ Silhouette } & \multicolumn{3}{|c|}{ Label } & \multirow{2}{*}{$\begin{array}{c}\text { Mean year } \\
\text { of citee }\end{array}$} \\
\hline & & & TFIDF & $L L R$ & MI & \\
\hline 0 & 35 & 0.871 & service level | multiple risk & $\begin{array}{l}\text { global supply } \\
\text { chain }\end{array}$ & cross entropy & 2008 \\
\hline 1 & 30 & 0.857 & supplier development & $\begin{array}{l}\text { integrative } \\
\text { supply chain } \\
\text { model }\end{array}$ & $\begin{array}{l}\text { supply chain } \\
\text { security }\end{array}$ & 2005 \\
\hline 2 & 21 & 0.977 & case study | supply chain processes & $\begin{array}{l}\text { global supply } \\
\text { chain risk } \\
\text { management }\end{array}$ & $\begin{array}{l}\text { computational } \\
\text { analysis }\end{array}$ & 2003 \\
\hline 3 & 21 & 0.989 & $\begin{array}{l}\text { developing global supply chain } \\
\text { quality management }\end{array}$ & $\begin{array}{l}\text { quality } \\
\text { management }\end{array}$ & $\begin{array}{l}\text { multi-tier } \\
\text { global supply } \\
\text { chain }\end{array}$ & 2007 \\
\hline 4 & 21 & 0.786 & fairtrade labelling scheme & $\begin{array}{l}\text { input output } \\
\text { analysis }\end{array}$ & $\begin{array}{l}\text { multi-tier } \\
\text { global supply } \\
\text { chain }\end{array}$ & 2010 \\
\hline 5 & 21 & 0.867 & global trade & $\begin{array}{l}\text { supply chain } \\
\text { design }\end{array}$ & $\begin{array}{l}\text { industrial } \\
\text { district }\end{array}$ & 2000 \\
\hline 6 & 20 & 0.913 & greenhouse gas emission & co2 emission & change policy & 2011 \\
\hline 7 & 15 & 0.945 & greenhouse gas emission | steel & $\begin{array}{l}\text { international } \\
\text { trade }\end{array}$ & $\begin{array}{l}\text { global supply } \\
\text { chain }\end{array}$ & 2010 \\
\hline 8 & 12 & 1 & services | processes & $\begin{array}{l}\text { integrating } \\
\text { information }\end{array}$ & $\begin{array}{l}\text { global supply } \\
\text { chain }\end{array}$ & 2009 \\
\hline 9 & 11 & 0.967 & $\begin{array}{l}\text { corporate social responsibility } \\
\text { | environmental performance } \\
\text { measurement models }\end{array}$ & $\begin{array}{l}\text { voluntary } \\
\text { governance } \\
\text { mechanism }\end{array}$ & $\begin{array}{l}\text { global supply } \\
\text { chain }\end{array}$ & 2010 \\
\hline
\end{tabular}


Table 2. Outstanding references with frequency, centrality and burst score

\begin{tabular}{|l|c|c|l|l|}
\hline $\begin{array}{l}\text { Citation } \\
\text { counts }\end{array}$ & Centrality & Burst & References & Cluster \\
\hline 14 & 0.04 & 5.87 & Goetschalckx M, 2002, EUR J OPER RES, V143, P1 & 5 \\
\hline 14 & 0.06 & 3.71 & Meixell MJ, 2005, TRANSPORT RES E-LOG, V41, P531 & 5 \\
\hline 11 & 0.10 & 0.10 & Goh M, 2007, EUR J OPER RES, V182, P164 & 0 \\
\hline 9 & 0.05 & - & Tomlin B, 2006, MANAGE SCI, V52, P639 & 2 \\
\hline 9 & 0.31 & 0.31 & Kleindorfer PR, 2005, PROD OPER MANAG, V14, P53 & 1 \\
\hline 8 & 0.01 & - & Manuj I, 2008, J BUS LOGIST, V29, P133 & 0 \\
\hline 7 & 0.03 & 4.64 & Vidal CJ, 1997, EUR J OPER RES, V98, P1 & 5 \\
\hline 7 & 0.01 & - & Davis SJ, 2010, P NATL ACAD SCI USA, V107, P5687 & 6 \\
\hline 6 & 0 & - & $\begin{array}{l}\text { Norrman A, 2004, International Journal of Physical Distribution \& } \\
\text { Logistics Management, V34, P434 }\end{array}$ & 2 \\
\hline 6 & 0 & - & Craighead CW, 2007, DECISION SCI, V38, P131 & 1 \\
\hline 6 & 0.29 & - & Roth AV, 2008, J SUPPLY CHAIN MANAG, V44, P22 & 4 \\
\hline 6 & 0.03 & 3.42 & Harland C, 2003, J PURCH SUPPLY MANAG, V9, P51 & 2 \\
\hline 5 & 0.14 & - & Yeung ACL, 2008, J OPER MANAG, V26, P490 & 3 \\
\hline 4 & 0.32 & - & Carter CR, 2008, INT J PHYS DISTR LOG, V38, P360 & 1 \\
\hline 4 & 0.09 & - & Lee HL, 2002, CALIF MANAGE REV, V44, P105 & 2 \\
\hline 4 & 0.08 & - & Gunasekaran A, 2008, OMEGA-INT J MANAGE S, V36, P549 & 0 \\
\hline 4 & 0 & 3.42 & Arntzen BC, 1995, INTERFACES, V25, P69 & 5 \\
\hline 2 & 0.16 & - & Dietzenbacher E, 2013, ECON SYST RES, V25, P71 & 4 \\
\hline 2 & 0.15 & - & Hunt SD, 2008, J SUPPLY CHAIN MANAG, V44, P10 & 1 \\
\hline 2 & - & Braunscheidel MJ, 2009, J OPER MANAG, V27, P119 & 0 \\
\hline
\end{tabular}

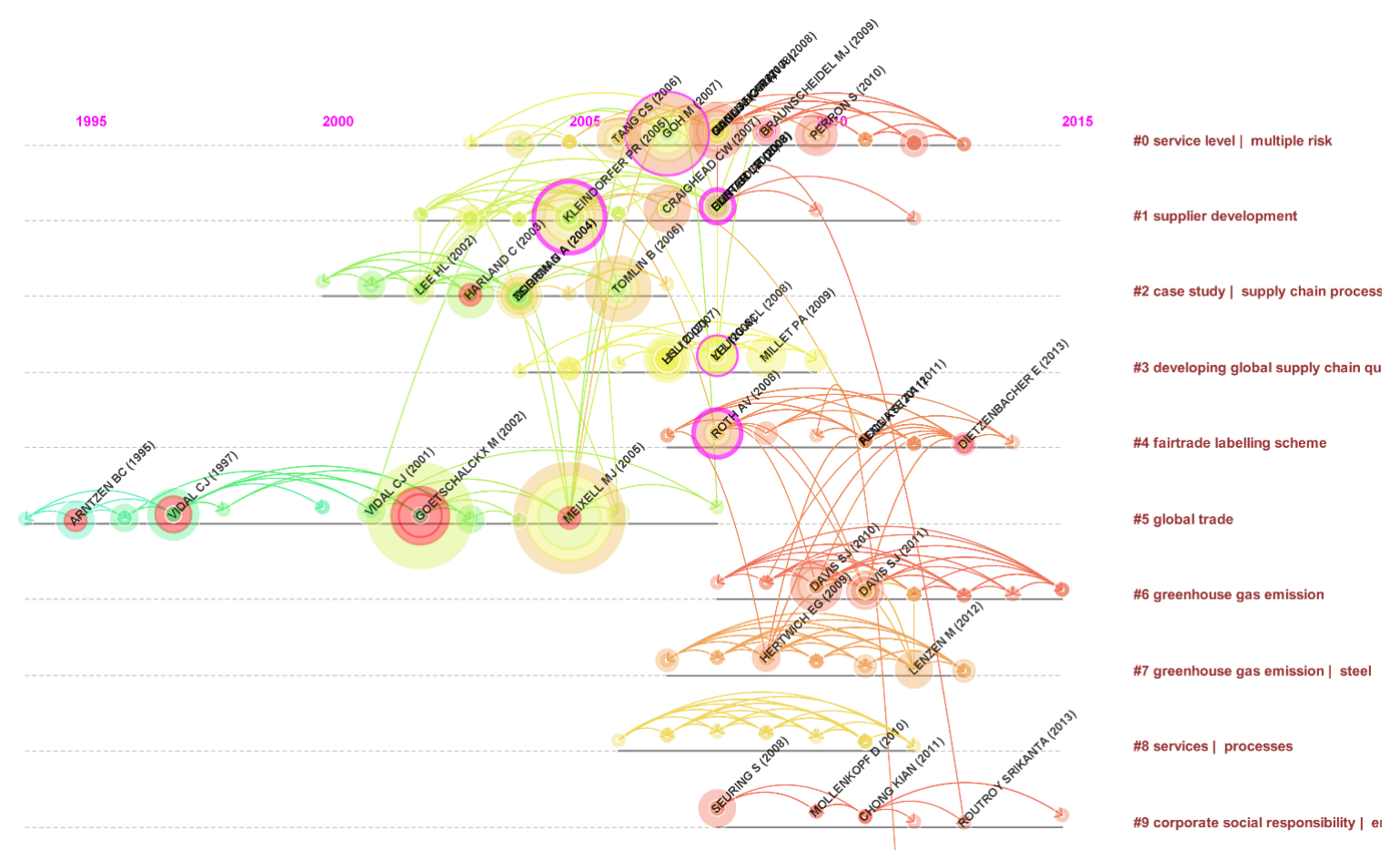

Figure 2. Timeline visualization of co-citation references 
In CiteSpace, it is possible to obtain a standard graph view as well as a time zone view, both of which facilitate some specific visual attributes with which researchers can interact. Figure 2 is the time zone view of the largest 10 clusters.

Figure 3 shows the visual results of a burst analysis. There are only five references that have burst scores in the dataset. Besides that, thanks to relatively high frequency and centrality scores, these papers also compound the basic theoretical infrastructure of the research field (see Table 2). However, all the burst references come from before 2010. This result indicates that recent studies do not catch the attention of other researchers.

\begin{tabular}{llllll}
\multicolumn{1}{c}{ References } & \multicolumn{1}{c}{ Year } & Strength Begin & End & $1995-\mathbf{2 0 1 6}$ \\
GOETSCHALCKX M, 2002, EUR J OPER RES, V143, P1, DOI & 2002 & $\mathbf{5 . 8 6 7 9}$ & 2005 & 2010 \\
VIDAL CJ, 1997, EUR J OPER RES, V98, P1, DOI & 1997 & $\mathbf{4 . 6 4 1 5}$ & 2002 & 2004 \\
MEIXELL MJ, 2005, TRANSPORT RES E-LOG, V41, P531, DOI & 2005 & $\mathbf{3 . 7 0 9 1} 2009$ & 2010 \\
ARNTZEN BC, 1995, INTERFACES, V25, P69, DOI & 1995 & $\mathbf{3 . 4 1 9 6} 1998$ & 2002 \\
HARLAND C, 2003, J PURCH SUPPLY MANAG, V9, P51 & 2003 & $\mathbf{3 . 4 1 7 5}$ & 2008 & 2009 \\
\hline
\end{tabular}

Figure 3. Top 5 references with the strongest citation burst

\section{Discussion}

Figure 1 shows the essential framework of a cognitive map consisting of global trade, service level/multiple risks, supplier development, and supply chain process clusters. Also, these clusters widely overlap in a nested manner. Thus, the majority of papers regarding these sub-topics depend on a very close intellectual basis. Furthermore, corporate social responsibility, the fair-trade labeling scheme, and greenhouse gas emission are the underlying subsidiary research clusters bonded to the main body in the cognitive map. Figure 2 also shows the timeline visualization of cited references. In this graph, it is easy to assess whether the sub-research fields are unsaturated or mature as well as classical or new trends.

In the global trade cluster, Meixell and Gargeya (2005) demonstrate that research needs to tackle multi-tier supply chains involving internal manufacturing and external supplier locations in a larger variety of industry settings (i.e. aircraft, heavy machinery, and services). Global supply chain designs should tackle outsourcing, integration and strategic alignment. Goetschalckx, Vidal, and Dogan (2002) articulate the cost-saving potential in the integration of transfer prices and production-distribution allocations into the global supply chain networks. Vidal and Goetschalckx (1997) describe several mathematical strategic production-distribution models for global supply chain design, highlighting their contribution and constraints. The remarkable drawback of these models is a lack of flexibility to adapt the continuous redesigning of the global supply chain.

In the service level/multiple risk cluster Goh, Lim, and Meng (2007) proposed a stochastic model for multi-stage global supply chain problems with profit maximization and risk minimization, namely supply, demand, exchange, and disruption. Perron, Hansen, Le Digabel, and Mladenović (2010) also attempt to maximize the global profit by determining the flow of goods, transfer prices and transportation cost allocation between each of its subsidiaries. 
In the supplier development cluster, Kleindorfer and Saad (2005) handle risks arising from disruptions to normal activities and provide a conceptual framework for risk assessment and risk mitigation. These kinds of risk factors include natural disasters, such as strikes and economic disruptions, as well as acts of purposeful agents, including terrorists. Craighead, Blackhurst, Rungtusanatham, and Handfield (2007) explain how and why some supply chain disruptions regarding operational and financial risks would be more severe than others . Tomlin (2006) argues the optimal disruption risk mitigation strategies that a risk-neutral firm can adopt in different scenarios. A supplier's percentage uptime and the nature of the disruptions are found to be the key determinants of optimal strategy. In case the supplier is unreliable, and the capacity is infinite, a mixed mitigation strategy can be the optimal one. Similarly, if a reliable supplier can ramp up its processing capacity of a contingent, rerouting is another possible tactic that remarkably reduces the firm's costs. Carter and Rogers (2008) introduce the concept of sustainable supply chain management based on resource dependence theory and exhibit the relationships among environmental, social, and economic performance within this concept. This paper has one of the most strategic positions in the network (see Table 2). As seen in the cognitive map, this paper stands on the hottest line of connection between the clusters of corporate social responsibility, service level/multiple risks, and global trade clusters.

In the case study/supply chain processes cluster, Harland, Brenchley, and Walker (2003) describe and classify the type of risks that threaten the supply network, within a holistic and managerial point of view.

In the greenhouse gas emission cluster, Davis and Caldeira (2010) present a global consumption-based $\mathrm{CO}_{2}$ emission inventory, derived from import and export of goods and services, in contrast with production- based $\mathrm{CO}_{2}$ emission. It is found that $23 \%$ of global $\mathrm{CO}_{2}$ emissions resulted from international trade in 2004. Consumption-based accounting reveals that a substantial amount of carbon leakage occurs in international trade. The direction of emissions mostly originates in China and other emerging markets and is passed on to consumers in the USA, Western Europe, and Japan. Sharing responsibility among producers and consumers could facilitate an international agreement on global climate policy, in order to compensate for regional emissions inequality. . Davis, Peters, and Caldeira (2011) challenge the myths that $\mathrm{CO}_{2}$ emissions from the burning of fossil fuels derive from the country where the emission is produced (i.e. where the fuels are burned). According to statistics, 37\% of global emissions are from fossil fuels that are internationally traded, and $23 \%$ of emissions come from traded goods. In consequence, it is important to discuss how to reduce carbon leakage along the global supply chain. . Hertwich and Peters (2009) illustrate the quantities of greenhouse gas emissions, regarding the consumption rates of goods and services in 73 nations and 14 world regions. The categories of consumption are construction, shelter, food, clothing, mobility, manufactured products, services, and trade. As results show , 72\% of emissions are associated with household consumption, $10 \%$ with government consumption, and $18 \%$ with investment. $20 \%$ of greenhouse gas emission is because of food, $19 \%$ because of operations and maintenance, and $17 \%$ because of mobility. Food and services are prominent for developing countries, whereas mobility and manufactured goods accelerate 
in rich countries. Politicians do not understand the significance of public services and manufactured goods.

In the fair-trade labeling scheme cluster, Lenzen et al. (2012) demonstrates how international trade chains along complex routes and consumers with demands for commodities drive biodiversity habitat degradation . Results showed that $30 \%$ of threats are because of international trade. In this perspective, it could be better to handle biodiversity loss as a global systematic phenomenon than by just looking at degrading or polluting producers in isolation. To describe the food supply chain and disruption, Roth, Tsay, Pullman, and Gray (2008) developed a conceptual framework containing traceability, transparency, testability, time, trust, and training points, which are critical factors to assure preservation of public health-care through a safe food supply. This study touches upon the food-related quality risk as well as contemporary research topics, i.e. ethical concerns. Therefore, this study bridges middle period clusters to recent period clusters as a strategic turning point in the cognitive map. Dietzenbacher et al. (2013) introduce The World Input-Output Database (WIOD) project. This database involves the subject associated with fragmentation and socio-economic aspects (i.e. water usage, energy usage and emissions to air). Moreover, it contains indicators related to the input of operations, such as capital and labor, as well as pollution derived from industrial activities like greenhouse gas emissions.

In the corporate social responsibility cluster, Seuring and Müller (2008) indicate that research is dominated by green/sustainable supply chain issues. However, social aspects and three dimensions of sustainability are overlooked by scholars. Halldórsson et al. (2010) examine the relationships among green, lean, and global supply chain strategies through a comprehensive literature review. In consequence, four major required themes are suggested: theoretically grounded research, multi-functional approaches, a systemic approach that adds strategic insight and integrated measurement applications.

\section{Conclusion}

The main objective of this study is to reveal how the domain knowledge of global supply chain growth has evolved over time. For this purpose, the document co-citation analysis was applied via CiteSpace. We believe that the results reveal a sufficient amount of clues to more easily grasp the gist of the literature.

As a result of this study, intellectually leading papers, as well as sub research fields, are determined via document co-citation analysis. As the timeline indicates, the knowledge domain of global supply chain research is divided into three periods. In the earlier period, research gathered in global trade is the oldest cluster. Research in this cluster mostly focuses on how to maximize after-tax profits and minimize costs for multinational corporations. Mathematical models are the prominent tools for achieving these goals. In the middle period, the main objective of studies slides towards risk assessment and mitigation in global supply networks. In the recent period three original research fields appear: greenhouse gas emissions, corporate social responsibility, and the fair-trade labeling scheme. Environmental issues and sustainability within global supply chains have become very popular in the recent period. Therefore, these sub-topics are the emerging trends in global supply chain literature. 
However, results indicate a lack of burst- cited references in emerging clusters. In other words, the papers in emerging trends are incapable of calling attention to themselves quickly. When the content of these references is examined, it can be seen that they only describe the contemporary problems of global supply chains. They are incapable of producing effective ideas to solve these problems. In order for these requirements to be met, theoretically grounded frameworks need to be developed. Thus future research may address this gap in the literature.

The apparent limitation of this study is that only the WoS database was used for collecting data. Although WoS assures the quality of papers, scanning other databases would enrich the quantity of the dataset. In that case, results may depict a more comprehensive grasp of the literature, which may be a further result of this research.

Peer-review: Externally peer-reviewed.

Conflict of Interest: The authors have no conflict of interest to declare.

Grant Support: The authors declared that this study has received no financial support.

Acknowledgement: An earlier version of this paper was presented at the International Conference on Economics and Management EMAN 2017: Globalization Challenges, held in Ljubljana, Slovenia, March 30, 2017.

\section{References}

Al, U., Sezen, U., and Soydal, İ. (2012). “Türkiye'nin bilimsel yayınlarının sosyal ağ analizi yöntemiyle değerlendirilmesi,” Ankara: (110K044).

Carter, C. R., and Rogers, D. S. (2008). "A framework of sustainable supply chain management: moving toward new theory," International Journal of Physical Distribution \& Logistics Management, 38(5), 360-387.

Chen, C., Ibekwe-SanJuan, F., and Hou, J. (2010). "The structure and dynamics of cocitation clusters: A multiple-perspective cocitation analysis," Journal of the American Society for Information Science and Technology, 61(7), 1386-1409.

Chen, C., and Leydesdorff, L. (2014). "Patterns of connections and movements in dual-map overlays: A new method of publication portfolio analysis," Journal of the Association for Information Science and Technology, 65(2), 334-351.

Chen, C., Song, I.-Y., Yuan, X., and Zhang, J. (2008). "The thematic and citation landscape of data and knowledge engineering (1985-2007)," Data \& Knowledge Engineering, 67(2), 234-259.

Colepicolo, E. (2015). "Information reliability for academic research: review and recommendations," New Library World, 116(11/12), 646-660.

Craighead, C. W., Blackhurst, J., Rungtusanatham, M. J., and Handfield, R. B. (2007). “The severity of supply chain disruptions: design characteristics and mitigation capabilities," Decision Sciences, 38(1), 131-156.

Crane, D. (1969). "Social structure in a group of scientists: A test of the" invisible college" hypothesis," American Sociological Review, 335-352.

Davis, S. J., and Caldeira, K. (2010). “Consumption-based accounting of CO2 emissions," Proceedings of the National Academy of Sciences, 107(12), 5687-5692.

Davis, S. J., Peters, G. P., and Caldeira, K. (2011). "The supply chain of CO2 emissions," Proceedings of the National Academy of Sciences, 108(45), 18554-18559.

Dietzenbacher, E., Los, B., Stehrer, R., Timmer, M., and De Vries, G. (2013). “The construction of world input-output tables in the WIOD project," Economic Systems Research, 25(1), 71-98. 
Ding, Y. (2011). "Scientific collaboration and endorsement: Network analysis of coauthorship and citation networks," Journal of Informetrics, 5(1), 187-203.

Gereffi, G., Humphrey, J., and Sturgeon, T. (2005). "The governance of global value chains," Review of International Political Economy, 12(1), 78-104.

Goetschalckx, M., Vidal, C. J., and Dogan, K. (2002). "Modeling and design of global logistics systems: A review of integrated strategic and tactical models and design algorithms," European Journal of Operational Research, 143(1), 1-18.

Goh, M., Lim, J. Y., and Meng, F. (2007). "A stochastic model for risk management in global supply chain networks,” European Journal of Operational Research, 182(1), 164-173.

Gunasekaran, A., Lai, K.-h., and Cheng, T. E. (2008). "Responsive supply chain: a competitive strategy in a networked economy," Omega, 36(4), 549-564.

Halldórsson, Á., Kovács, G., Mollenkopf, D., Stolze, H., Tate, W. L., and Ueltschy, M. (2010). "Green, lean, and global supply chains," International Journal of Physical Distribution \& Logistics Management, $40(1 / 2), 14-41$.

Harland, C., Brenchley, R., and Walker, H. (2003). "Risk in supply networks," Journal of Purchasing and Supply management, 9(2), 51-62.

Hertwich, E. G., and Peters, G. P. (2009). "Carbon footprint of nations: A global, trade-linked analysis," Environmental Science \& Technology, 43(16), 6414-6420.

Kaufman, L., and Rousseeuw, P. J. (2009). Finding groups in data: an introduction to cluster analysis (Vol. 344): John Wiley \& Sons.

Klavans, R., and Boyack, K. W. (2011). "Using global mapping to create more accurate document-level maps of research fields," Journal of the American Society for Information Science and Technology, 62(1), 1-18.

Kleindorfer, P. R., and Saad, G. H. (2005). "Managing disruption risks in supply chains," Production and Operations Management, 14(1), 53-68.

Lenzen, M., Moran, D., Kanemoto, K., Foran, B., Lobefaro, L., and Geschke, A. (2012). “International trade drives biodiversity threats in developing nations," Nature, 486(7401), 109-112.

Meixell, M. J., and Gargeya, V. B. (2005). "Global supply chain design: A literature review and critique," Transportation Research Part E: Logistics and Transportation Review, 41(6), 531-550.

Perron, S., Hansen, P., Le Digabel, S., and Mladenović, N. (2010). "Exact and heuristic solutions of the global supply chain problem with transfer pricing," European Journal of Operational Research, 202(3), 864-879.

Pritchard, A. (1969). "Statistical bibliography or bibliometrics," Journal of Documentation, 25, 348.

Rorissa, A., and Yuan, X. (2012). "Visualizing and mapping the intellectual structure of information retrieval," Information Processing \& Management, 48(1), 120-135.

Roth, A. V., Tsay, A. A., Pullman, M. E., and Gray, J. V. (2008). "Unraveling the food supply chain: strategic insights from China and the 2007 recalls," Journal of Supply Chain Management, 44(1), 22-39.

Seuring, S., and Müller, M. (2008). "From a literature review to a conceptual framework for sustainable supply chain management," Journal of Cleaner Production, 16(15), 1699-1710.

Simovici, D. (2007). "Data Mining Algorithms I: Clustering," Handbook of Applied Algorithms, 177-218.

Small, H. (1973). "Co-citation in the scientific literature: A new measure of the relationship between two documents, " Journal of the Association for Information Science and Technology, 24(4), 265-269.

Tomlin, B. (2006). "On the value of mitigation and contingency strategies for managing supply chain disruption risks," Management Science, 52(5), 639-657.

Vidal, C. J., and Goetschalckx, M. (1997). "Strategic production-distribution models: A critical review with emphasis on global supply chain models," European Journal of Operational Research, 98(1), 1-18.

Yalçin, H., and Yayla, K. (2016). "Scientometric Analysis of the Researches About Technological Pedagogical Content Knowledge and Scholarly Communication," Egitim ve Bilim, 41(188). 
Yeung, A. C. (2008). "Strategic supply management, quality initiatives, and organizational performance," Journal of Operations Management, 26(4), 490-502.

Zhang, Q., Wang, Q., Hao, J. X., and Yu, Y. (2016, 2016 / 08 / 09 /). "Mapping smart tourism research in China: A semantic and social network analysis using CiteSpace". Paper presented at the 13th International Conference on Service Systems and Service Management.

Zuccala, A. (2006). "Modeling the invisible college," Journal of the Association for Information Science and Technology, 57(2), 152-168. 